\title{
Research on the Subsidy Policy of Wind Energy Price in Shandong Province Based on CGE Model
}

\author{
Yangxiao Wang, Qiufang Fan*, Ying Ma, Jie Zhang \\ Department of Economics, School of Economics and Management, China University of Petroleum (East China), Qingdao, China \\ Email address: \\ bankwyx@163.com(Yangxiao Wang),fanqf@upc.edu.cn (Qiufang Fan),my8125@163.com(Ying Ma), zjiedream@163.com (Jie Zhang) \\ ${ }^{*}$ Corresponding author
}

\section{To cite this article:}

Yangxiao Wang, Qiufang Fan, Ying Ma, Jie Zhang. Research on the Subsidy Policy of Wind Energy Price in Shandong Province Based on CGE Model. International Journal of Economics, Finance and Management Sciences. Vol. 8, No. 5, 2020, pp. 205-213.

doi: $10.11648 /$ j.ijefm.20200805.15

Received: September 5, 2020; Accepted: September 23, 2020; Published: October 20, 2020

\begin{abstract}
In recent years, with the improvement of wind power generation technology and industrial upgrading, China's wind power generation manufacturing and application scale ranks among the top in the world. Technological advances in these related fields have reduced costs, making renewable energy an important area of the energy transition. At present, renewable energy mainly includes wind, solar and biomass energy. Among them, wind energy has the advantages of wide sources, low cost, advanced energy capture and conversion technology and equipment, which make it has been applied in many places on a large scale. By contrast, due to the difficulty of material recovery and high cost, the large-scale application of biomass energy is limited Meanwhile, the production of solar panels is characterized by high pollution and high energy consumption, which is not environmentally friendly and limits its industrial expansion. Therefore, this research will focus on wind power price related policies in Shandong Province. In this paper, a Computable General Equilibrium (CGE) model of renewable energy policy according to the current development in Shandong Province was first built. Then, by simulating the increase of wind energy electricity price subsidies by $5 \%, 10 \%, 15 \%, 20 \%, 25 \%, 30 \%$ compared with the base year, the effects of electricity price subsidies on energy, economics, social and environment were further analyzed. Finally, suggestions were proposed which can provide a reference for the promotion and development of wind energy in Shandong Province.
\end{abstract}

Keywords: Wind Energy, CGE Model, Electricity Price Subsidies, Energy Effect, Economic Effect, Social and Environmental Effect

\section{Introduction}

With the rapid development of economy, the demand for energy in nowadays society is increasing continuously. Compared with traditional energy sources such as oil and coal, wind energy have obvious advantages in terms of source, environmental protection and sustainability, which makes it considered an important part of the future energy development structure. It has always been important energy sources for human survival, and occupying an important position in the whole energy system. Due to such characteristics of reproducibility, low pollution, wide distribution, abundant quantity, advanced technologies and equipment for energy capture and conversion and so on, it has been used in many places for large-scale applications [1].

In order to reduce costs, closely combine research and application, and build a complete wind energy industry chain, China government has issued a series of policies, such as gradually implementing the construction of low-cost projects, connecting wind power generation and power transmission projects, adjusting the benchmark on-grid price of wind power generation, and implementing different subsidy prices for different resource areas. Shandong province implements different electricity price subsidies every year, in order to improve the quality of wind energy generation, energy efficiency, economic benefits, social and environmental benefits. And further study and discuss the most reasonable amount of wind energy price subsidies for the development of the industry [2,3].

In terms of CGE model application, Johansen constructs the first relatively complete general equilibrium model, divides the CGE model structure into more than 20 industrial sectors, and clarifies the specific solution method of each part 
of the model [4]. Dixon P. B, Jerie M, Rimmer M. T improves the traditional CGE model and imposes theoretically optimized structures on unobstructed variables, paving the way for estimation [5]. Based on the traditional CGE model, Gao Yang, Wang Xiaoyue et al. added water pollution purification elements into the structure, and studied the impact of different purification coefficients on China's overall economic sectors from the perspectives of supply and demand [6]. Hu Qing established a CGE model of the impact of carbon tax policies on China's economy, studied the impact of different carbon tax rates on economic indicators such as industrial economic structure, energy consumption and price, and carbon emissions, and finally found that carbon tax was inversely proportional to macroeconomic indicators [7]. In terms of electricity price subsidy, Zhang Yu established a CGE model related to wind power price subsidy, formulated an optimization plan centering on wind power price, and proposed a solution to the resistance encountered in the implementation of electricity price policy [8]. Lin Fang combined fiscal policy and tax policy, established regional ENERGY and environment CGE model, set up different policy optimization schemes, implemented fixed and progressive fiscal subsidies and corresponding tax policies, and analyzed their impact on the economy and environment of Mongolia in the energy region [9]. Using the economic data of northeast China, Wang Peng constructed a CGE model including industries, economic actors and production factors, and evaluated the impact of different carbon tax rates on economic parties. The implementation of carbon tax will not only promote technological progress and improve energy efficiency, but also bring changes in industrial structure and household consumption structure [10]. Zhang Wenjing established a multi-regional dynamic CGE model, which divides China into nine regions and divides the country into two groups according to the severity of smog: high-pollution areas and low-pollution areas. Different simulation scenarios were set to evaluate the policy impact from multiple dimensions such as air quality, tax rate, emission reduction cost and total output of various industries [11].

Combined with the present situation and existing problems of energy development in Shandong province, this paper chooses Computable General Equilibrium (CGE) model. The theoretical basis of this model is relatively complete, and it has been widely used in policy analysis. In order to simulate and analyze renewable energy policies from the perspective of regulating energy subsidies, we first increased wind energy subsidies by $5 \%, 10 \%, 15 \%, 20 \%, 25 \%$ and $30 \%$ respectively at the base year level. Then, the effects of different subsidies on energy consumption, energy prices, social economy and ecological environment were further investigated. And finally we put forward such feasible suggestions for the healthy development of wind energy in Shandong province.

\section{Research Methodology}

The Computable General Equilibrium (CGE) model, based on the Walras General Equilibrium theory, has developed over 40 years to become a fairly canonical model for policy analysis. Generally speaking, a typical CGE model uses a set of equations to describe the relationship between supply, demand and market. Under the constraint of a series of optimization conditions, a set of supply and demand quantities and market prices can be obtained through the equations to make the market reach equilibrium state [12].

\subsection{The Social Accounting Matrix (SAM)}

As the primary data source of CGE model, SAM most refer to input-output tables and other related statistical data [13]. It is usually built in three steps. The first step is to determine the specific account structure of the SAM table. The second step is to determine the specific data of each account based on the input-output table and other data. The third step is to subdivide the "commodity account" according to the specific research object. The resulting macroscopic and detailed SAM tables serve as the data base for the subsequent models and programming.

The compilation of Shandong Province's wind energy SAM must first determine the base year. Since the latest input-output tables in Shandong Province is 2012, and most of the data in the Shandong Province's wind energy SAM table comes from these input-output tables, 2012 is selected as the base year. The data sources mainly include two parts, the first part comes from "Shandong Province 42 Departments' Input-Output Tables", "Shandong Financial Yearbook", and "Shandong Statistical Yearbook", the second part comes from "China Rural Statistical Yearbook" and "China Tax Yearbook". The foreign account data are the values after the exchange rate treatment for the year.

\subsection{CGE Model Structure for Wind Energy Price Subsidies}

Researchers can determine the specific structure of the model according to research objects, data rationality and other comprehensive factors. In addition, the data can be split and recombined according to the actual need, and finally a CGE model suitable for wind energy price subsidy in Shandong province can be obtained. As a key factor of production in this study, energy module is introduced into the CGE model. Moreover, coal, oil, natural gas, thermal power, wind power, solar power, biomass power and other energy elements are also introduced. The overall framework of the CGE model is shown in Figure 1.

Here, based on the development status of wind energy in Shandong province, we divided the CGE model into 6 modules to represent the production, consumption and distribution activities, including energy module, production module, trade module, price module, income and consumption module, and macro equilibrium module, respectively. Among them, the energy module describes the input-output relationship of energy production in Shandong province. The production module describes the factor input in the production process, such as labor and capital, etc. Besides describing import and export commodities, the trade module increases the domestic 
trade relationship outside the province, which is also the characteristic of the provincial CGE model. The price module describes the price state of domestic and foreign factors of production and intermediate inputs. The income and consumption module describes the income and consumption of residents, enterprises and governments. Since some independent equations cannot be combined with some modules, a macroscopic equilibrium module is set up to balance the equations and variables of each module. The nested structures of partial modules are shown in the Figures 2-7. In these figures, the CES denotes constant elasticity of substitution function; CET denotes constant elasticity of transformation function, C-D denotes Cobb-Douglas function and Leontief denotes Leontief function. Because the CGE model involves a large number of variables and formulas, we will not list them in detail here [14-17].

\subsection{The CGE Model Parameters of Wind Power Price Subsidy}

The parameters of this model are mainly divided into two categories. The first is elastic parameters (mainly substitution elasticity), such as the demand substitution parameters of energy composite elements in the energy module. There are also Armington elastic parameters to describe the substitution between domestic products and imports, and CET elastic parameters to describe the substitution between import and export of domestic products. The second kind is the share parameter, such as the share coefficient of fossil energy elements and electric power elements in the energy module. The relevant elastic coefficients involved in this paper are shown in Table 1.

\section{Policy Simulation and Analysis of Electricity Price Subsidy}

Based on the CGE model constructed in the second part, we used General Algebraic Modeling System (GAMS) [18, 19] to program the entire policy simulation and analysis process. Specifically, the energy effect, economic effect, social and environmental effect of the wind price subsidy are analyzed when the subsidy increases by $5 \%$ to $30 \%$ at the base year level.

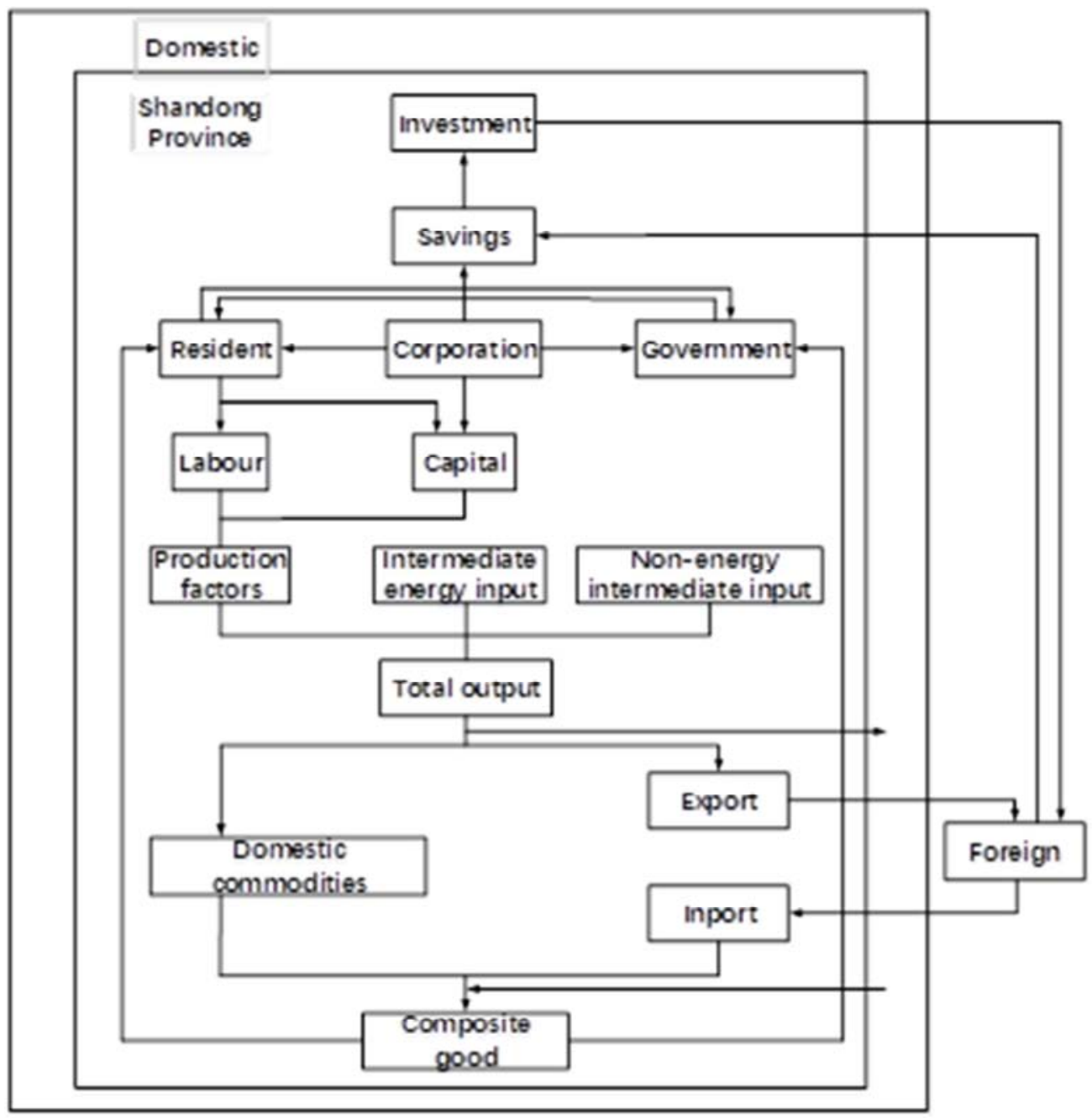

Figure 1. The overall framework of CGE model. 


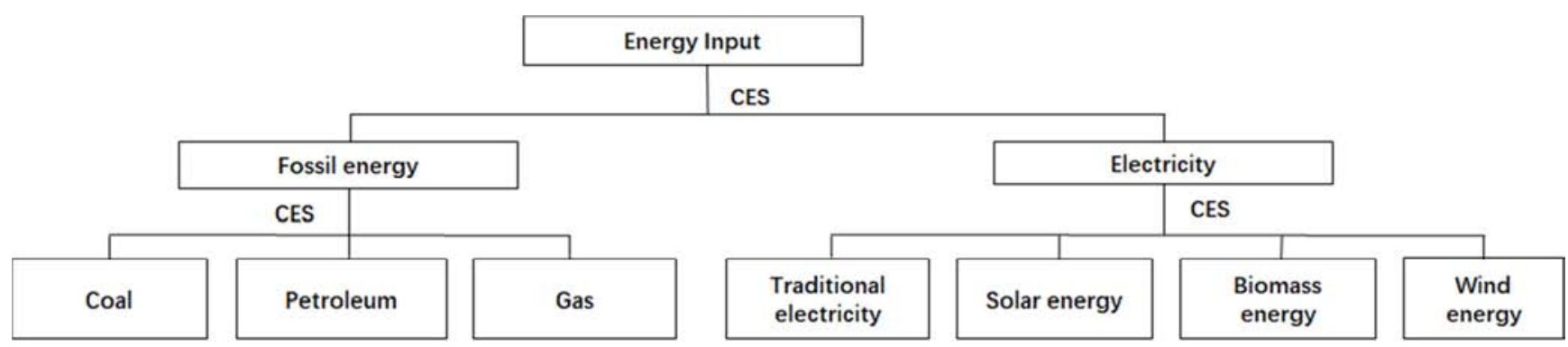

Figure 2. Nested structure of energy module.

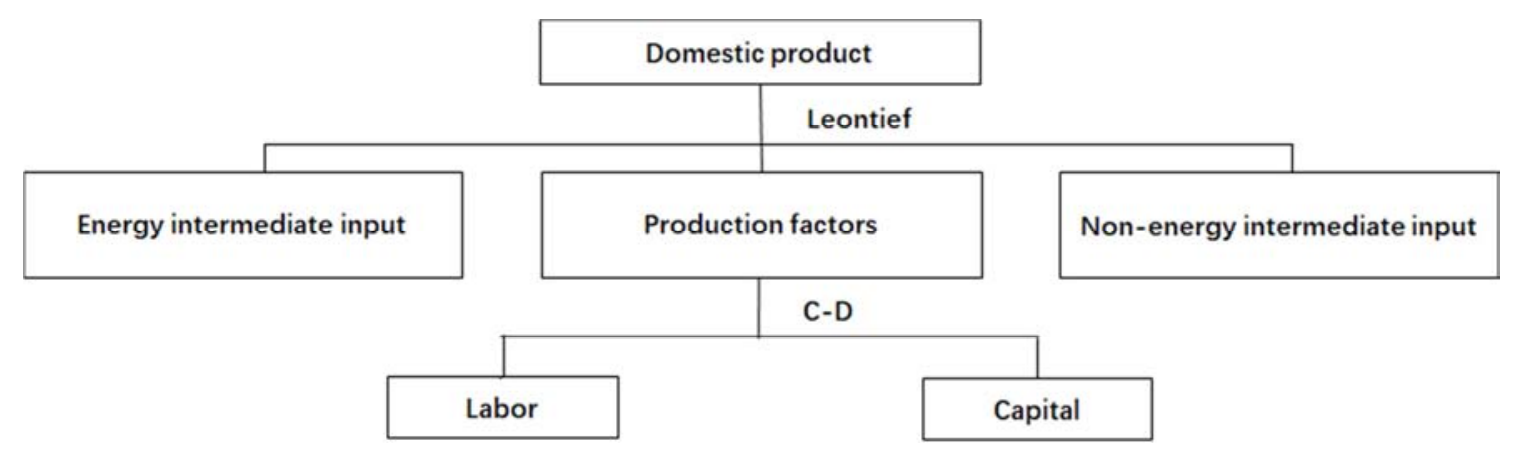

Figure 3. Nested structure of production module.

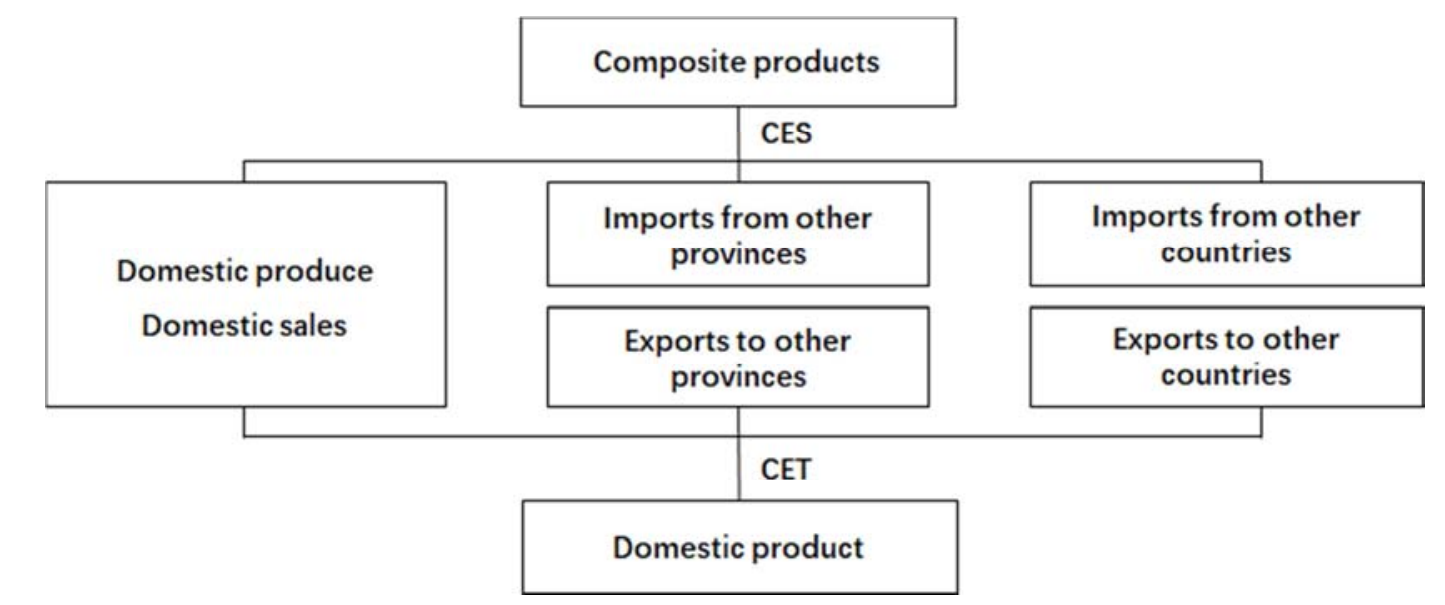

Figure 4. Nested structure of trade module.

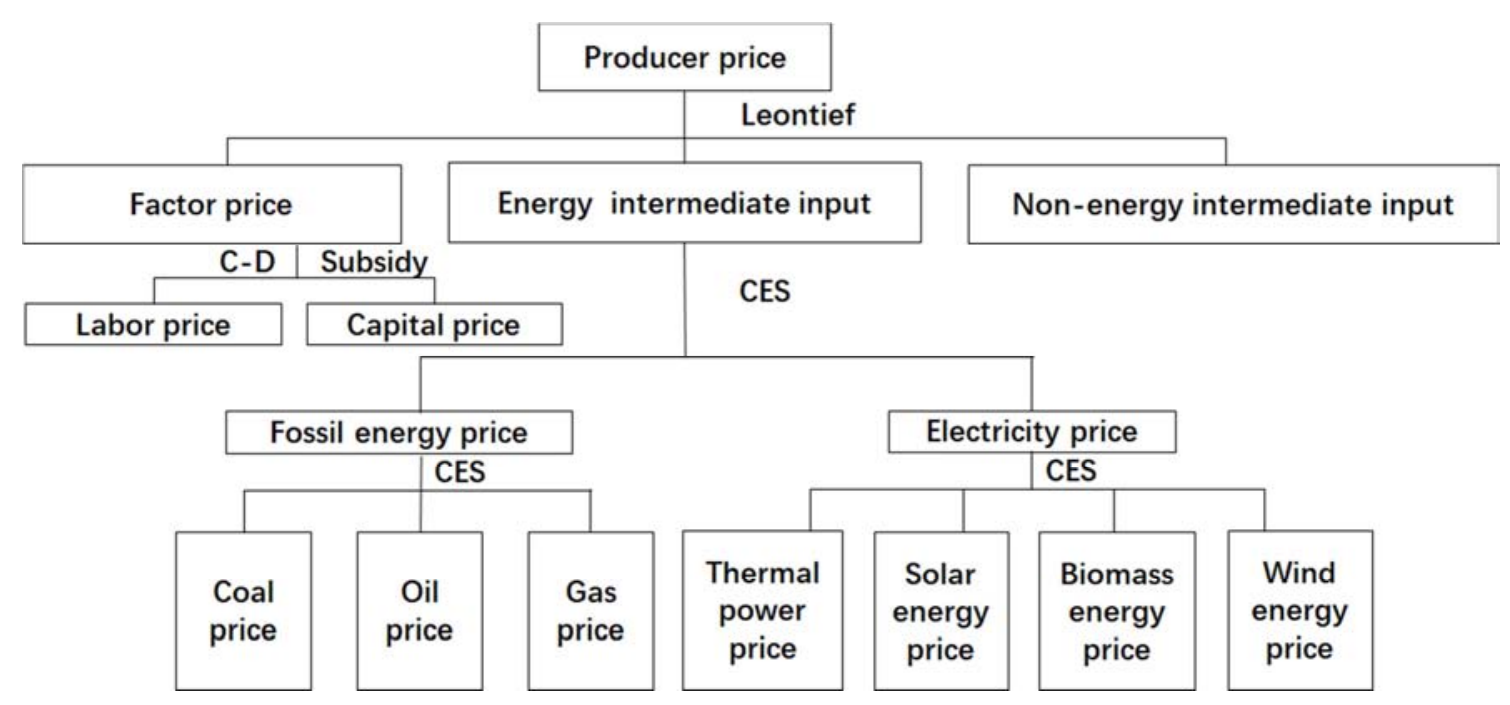

Figure 5. Nested structure of price module. 


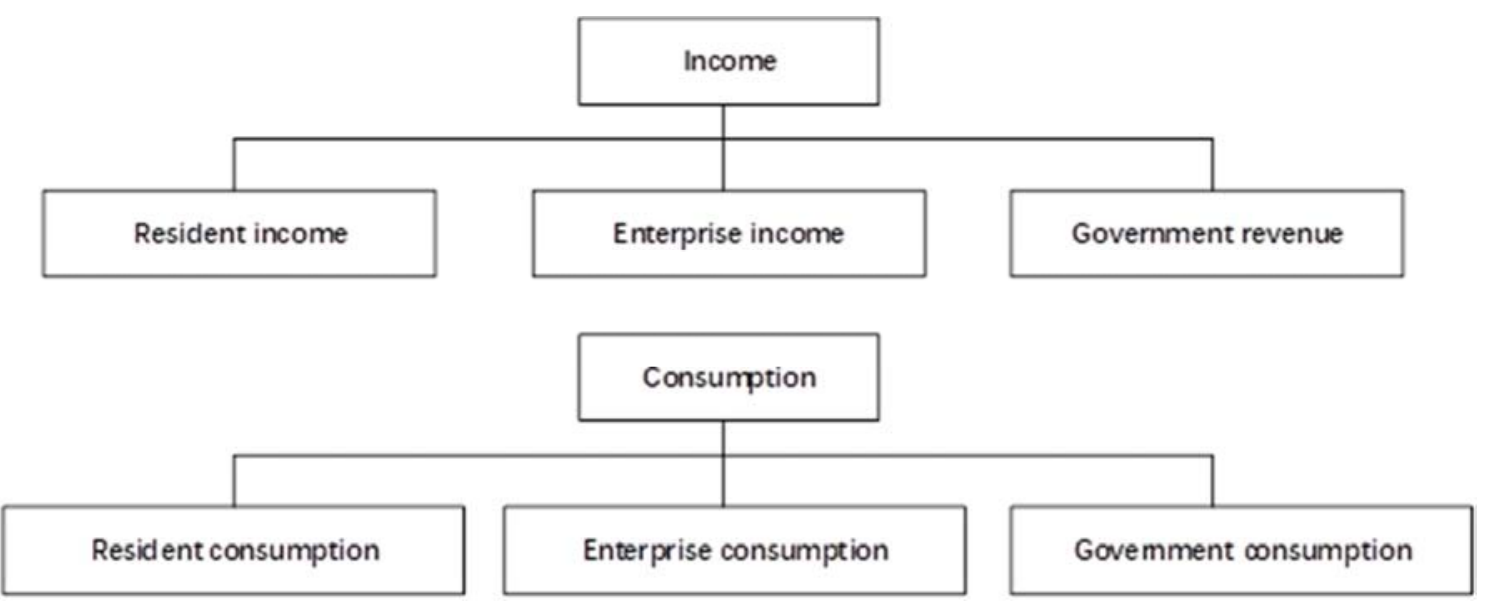

Figure 6. Nested structure of income and consumption module.

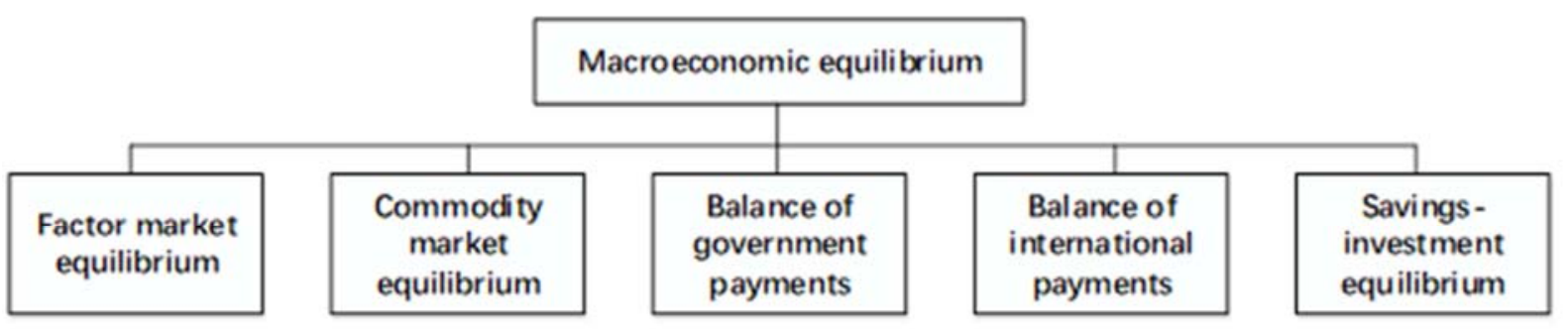

Figure 7. Nested structure of macroeconomic equilibrium.

\subsection{Assumptions and Scenario Settings}

Due to the setting requirements of the CGE model, we made the following assumptions before simulation.

1) The total employment in Shandong Province does not change with employers' salary;

2) As an open region, that the value of capital in Shandong Province will not change in the short term and the income of fixed capital will not change;

3) When simulating the subsidy rate, it is assumed that all the electricity produced by the wind energy can be fully received by the grid;

4) During the policy simulation period, renewable energy prices are fixed, but the government's power generation is determined by the market and is not mandatory;
5) The electricity price subsidy is determined according to the national onshore wind power standard price set by the National Development and Reform Commission. Wind power generation in Shandong province belongs to the national Level III resource zone, and the subsidy guiding electricity price is 0.49 yuan $/ \mathrm{KW} \cdot \mathrm{h}$ (tax included).

\subsection{The Effect of Wind Energy Price Subsidy Policy}

\subsubsection{The Energy Effect of Wind Energy Price Subsidy}

Based on the model simulation results, the change rates in the prices and consumption of various energy sources are shown in Table 2, and the impact trends of wind subsidies on energy prices and energy consumption are shown in Figure 8 and Figure 9, respectively.

Table 1. Relevant elasticity coefficient table.

\begin{tabular}{|c|c|c|c|c|c|c|c|c|c|c|c|}
\hline Parameter & Agricultural & Industry & $\begin{array}{l}\text { Construction } \\
\text { industry }\end{array}$ & $\begin{array}{l}\text { Service } \\
\text { industry }\end{array}$ & Coal & Oil & Gas & $\begin{array}{l}\text { Electri } \\
\text { power }\end{array}$ & $\begin{array}{l}\text { Wind } \\
\text { energy }\end{array}$ & $\begin{array}{r}\text { Biomas } \\
\text { energy }\end{array}$ & $\begin{array}{l}\text { Solar } \\
\text { energy }\end{array}$ \\
\hline Armington & 3 & 3 & 3 & 3 & 3 & 3 & 3 & 1.1 & 1.1 & 1.1 & 1.1 \\
\hline CET & 5 & 5 & 4 & 4 & 4 & 4 & 4 & 0.5 & 0.5 & 0.5 & 0.5 \\
\hline Fossil energy & 1.25 & 1.25 & 1.25 & 1.25 & 1.25 & 1.25 & 1.25 & 1.25 & 1.25 & 1.25 & 1.25 \\
\hline Electric power & 5 & 5 & 5 & 5 & 5 & 5 & 5 & 5 & 5 & 5 & 5 \\
\hline Energy & 0.6 & 0.6 & 0.2 & 0.25 & 0.5 & 0.5 & 0.5 & 0.1 & 0.1 & 0.1 & 0.1 \\
\hline
\end{tabular}

Table 2. The impact of wind energy price subsidies on energy price and consumption (unit: \%).

\begin{tabular}{llllll}
\hline Wind electricity price subsidy growth rate & $\mathbf{5}$ & $\mathbf{1 0}$ & $\mathbf{1 5}$ & $\mathbf{2 0}$ & $\mathbf{2 5}$ \\
\hline Coal price change rate & 0.14 & 0.28 & 0.47 & 0.92 & 0.32 \\
Oil price change rate & 0.06 & 0.11 & 0.21 & 0.46 \\
Gas price change rate & 0.03 & 0.06 & 0.12 & 0.21 & 0.32 \\
Electricity price change rate & 0.07 & 0.12 & 0.15 & 0.21 & 0.28 \\
Coal consumption change rate & -8.31 & -11.98 & -16.12 & -21.36 & -28.41 \\
Oil consumption change rate & -3.21 & -4.77 & -6.12 & -10.58 & -15.32 \\
\hline
\end{tabular}




\begin{tabular}{|c|c|c|c|c|c|c|}
\hline Wind electricity price subsidy growth rate & 5 & 10 & 15 & 20 & 25 & 30 \\
\hline Gas consumption change rate & -1.98 & -2.84 & -4.01 & -5.44 & -6.78 & -9.21 \\
\hline Electricity consumption change rate & 3.11 & 3.65 & 4.23 & 3.21 & 2.17 & 1.06 \\
\hline Wind energy consumption change rate & 27.56 & 31.38 & 39.95 & 45.44 & 51.29 & 58.05 \\
\hline
\end{tabular}

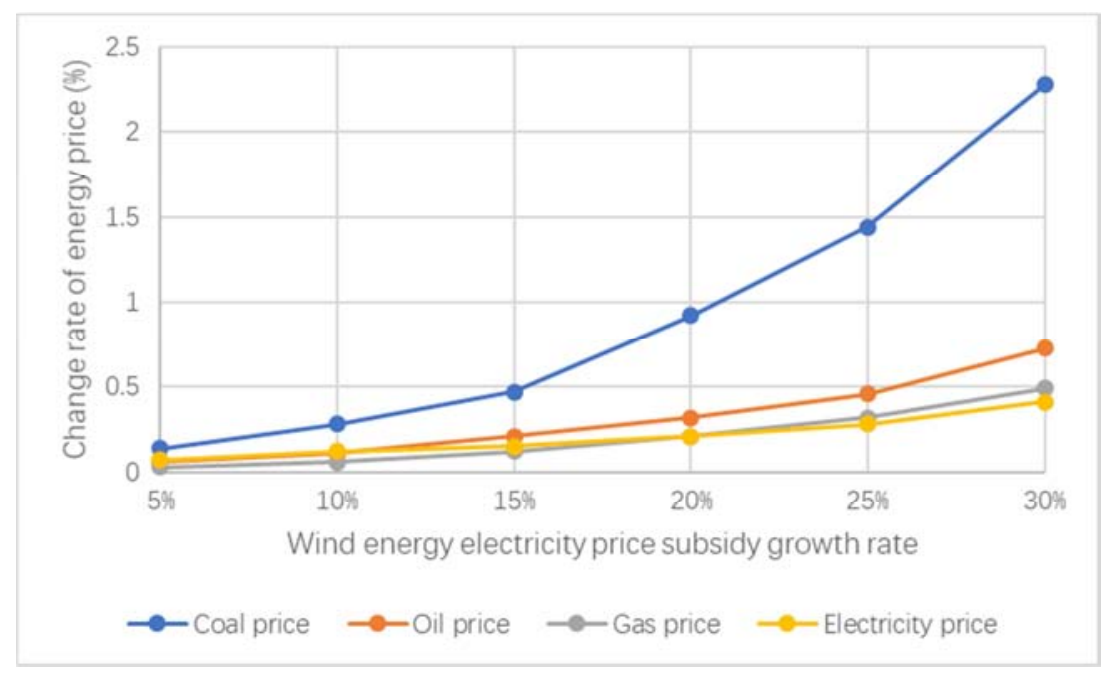

Figure 8. The impact of wind energy price subsidies on energy price.

From Figure 8, we can find that with the increase in wind energy price subsidies, the prices of various types of energy have increased to some extent. Among them, the growth rates of oil, natural gas and electricity prices are relatively small, around $0.06 \% \sim 0.73 \%, 0.03 \% \sim 0.49 \%$ and $0.07 \% \sim 0.41 \%$, respectively. Compared to oil, gas and electricity, the price of coal has a clear upward trend. Specifically, coal prices increased by $0.14 \%$ to $2.28 \%$.

The incentive effect of electricity price subsidy on wind energy consumption is very significant, and it has both income effect and substitution effect. On the one hand, under the premise that the total energy demand of Shandong province tends to be saturated, the increase of wind energy consumption is bound to be accompanied by the relative decline of fossil energy demand, therefore the electricity price subsidy makes the substitution relationship between wind energy and fossil energy. On the other hand, when income is constant, consumer purchasing power increased due to the existence of subsidies leads to increased consumption of wind power, thus generating income effect.

Figure 9 shows the impact of wind energy price subsidies on the changes in different types of energy consumption. We can see that the stimulating effect of electricity price subsidies on wind energy consumption is very obvious. Definitely, wind energy consumption has increased by $27.56 \% \sim 58.05 \%$. The consumption of traditional energy including coal, oil, gas has been reduced to a certain extent. Specifically, the decline in coal consumption is $8.31 \%$ to $35.88 \%$, oil is $3.21 \%$ to $21.80 \%$, and natural gas is $1.98 \%$ to $9.21 \%$. Also unlike fuel energy, the total electricity energy consumption will not change significantly.

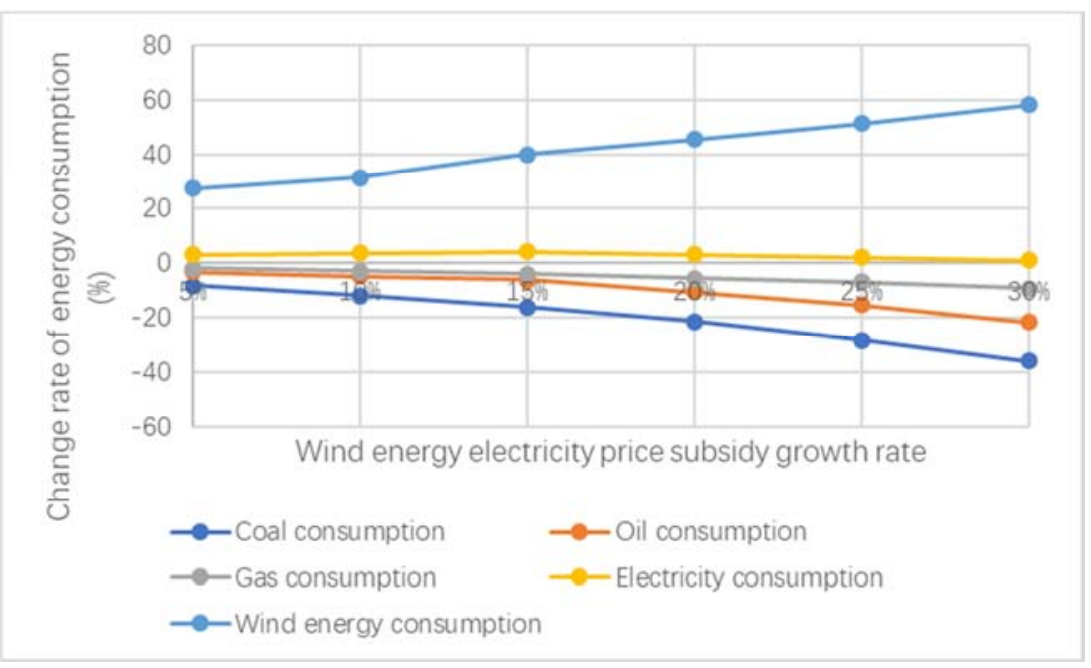

Figure 9. The impact of wind energy price subsidies on energy consumption. 
As shown in Figure 8 and Figure 9, energy consumption and price show a significant negative correlation, indicating that energy price is highly sensitive to the change of supply and demand in the energy market. When the energy consumption decreases, there will be an imbalance state between supply and demand in the short term. So when the amount of energy that can be traded is low, energy prices must reflect this scarcity and drive up energy prices.

\subsubsection{The Economic Effect of Wind Energy Price Subsidy}

The change of wind energy price subsidies will also have an impact on regional economic development. Here, we analyzed the change rate and trend of Shandong's GDP, as shown in Figure 10. We can see that with the increase of electricity price subsidies, the overall change of Shandong's GDP shows an "inverted U shape" at the inflection point when subsidy growth is $20 \%$. When the subsidy growth rate reaches to $30 \%$, the GDP growth rate is even equal to $5 \%$ subsidy growth rate. Therefore, if only from the perspective of economics, the growth rate of wind power subsidies should be set at near $20 \%$.

With the increase of wind power subsidy, its consumption and consumption proportion will increase, which will lead to increased investment and job creation. It will also stimulate the entire wind industry and boost GDP growth. However, excessive subsidies can bring some disadvantages, especially when projects are carried out far in excess of actual regional demand, such as excessive investment and overheating of the industry. The dislocation of resource allocation leads to partial loss of social welfare, and the marginal utility brought by subsidies is greatly reduced or even negative, which makes it difficult to optimize the industrial structure and maintain macroeconomic stability.

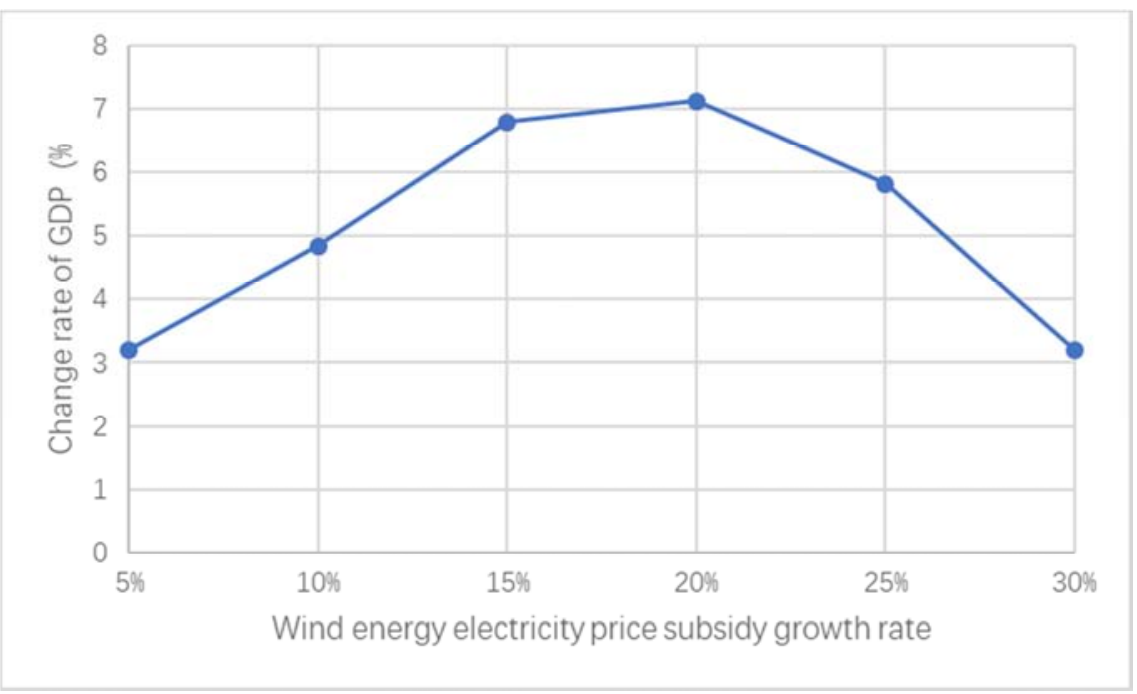

Figure 10. The impact of wind energy price subsidies on GDP of Shandong province.

\subsubsection{The Social and Environmental Effect of Wind Energy Price Subsidy}

Researchers also investigated the social and environmental effect of electricity price subsidies. The research objects here are mainly the social welfare level and carbon emission level, taking the change of residents' consumption level as the reference items of the change of the overall social welfare level, as shown in Table 3 and Figure 11.

It can be clearly seen from the table and figure that increasing the price subsidy for wind energy has a positive impact on the reduction of carbon emissions, which is consistent with our previous view that the price subsidy for wind energy promotes the transformation of energy consumption. However, it should be noted that the level of social welfare changes in the opposite direction to the level of carbon emissions. This is mainly because price subsidies increase the price of electricity through the mechanism of average allocation and affect the price of other energy through substitution. As households spend more on energy or electricity prices, their real purchasing power decreases with fixed incomes. Relatively speaking, the negative effect of wind power price subsidy on social welfare is significantly smaller than the positive effect on environmental benefits, and can even be ignored. Therefore, the influence of wind power price subsidy policy on different objects is different, which needs to be determined reasonably and prudently according to the actual situation.

Table 3. The impact of wind energy price subsidies on social and environmental indicator (unit: \%).

\begin{tabular}{llllll}
\hline Wind electricity price subsidy growth rate & $\mathbf{5}$ & $\mathbf{1 0}$ & $\mathbf{1 5}$ & $\mathbf{2 0}$ & $\mathbf{2 5}$ \\
\hline Social welfare & 0.09 & 0.17 & 0.31 & 0.22 & 0.06 \\
Carbon emission & -1.56 & -3.08 & -5.24 & -7.87 & -10.68 \\
\hline
\end{tabular}




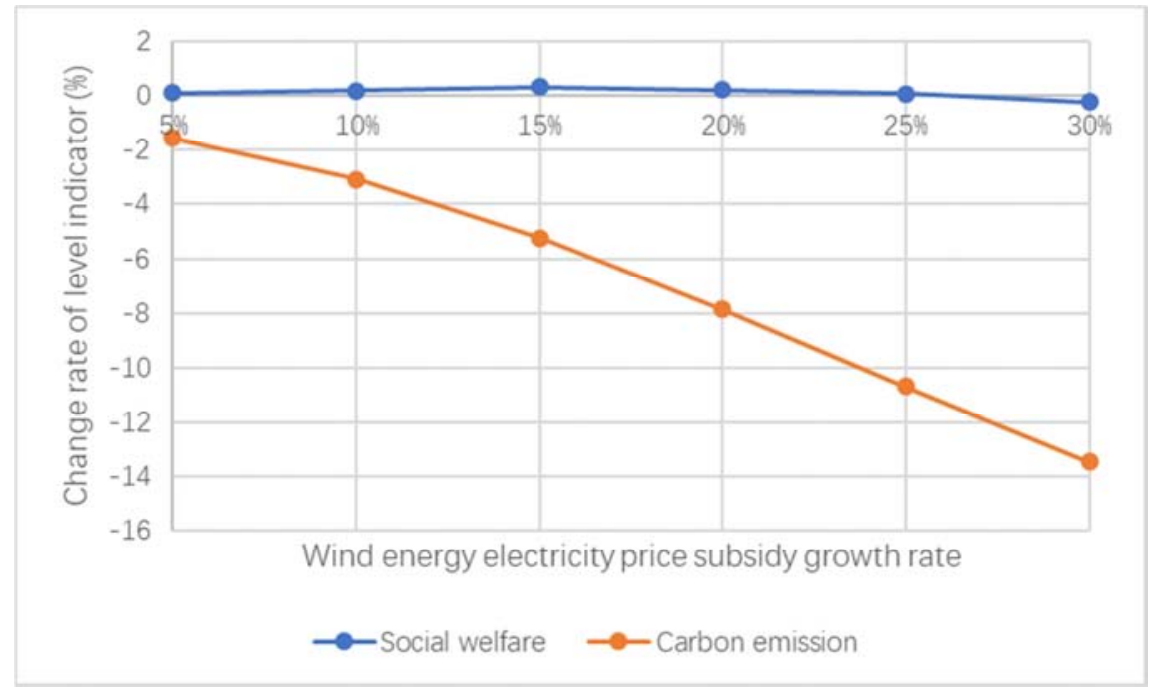

Figure 11. The impact of wind energy price subsidies on social and environmental indicator.

\section{Conclusions and Suggestions}

In this research a CGE model that complies with the characteristics of energy consumption and economic development in Shandong Province is first established. Then, the impact of changes in wind energy price subsidies on energy effect, economic effect, social and environmental effect of Shandong Province was investigated. The specific conclusions are shown as follow.

(1) The lower price subsidy plays a positive role in promoting economic development, while the higher subsidy level makes the MARGINAL negative growth of GDP. At this time, carbon emissions have been greatly reduced, and the reduction of consumption of traditional fossil energy has brought about positive environmental effects and negative social welfare effects. Therefore, in combination with the development level of relevant industries and the degree of environmental protection governance, in order to achieve the optimal overall welfare level, it is suggested that the subsidy target be set to increase by about $20 \%$ compared with the base year.

(2) Moderate electricity price subsidies will lead to the optimization of energy consumption structure, which will lead to increased investment and job creation. At the same time, as the capture of wind energy depends on large-scale professional equipment, it will also stimulate the development of the wind industry upstream. Industrial expansion and full employment raise disposable income, which in turn stimulates consumption to achieve healthy GDP growth.

(3) Although wind power price subsidies can significantly reduce coal consumption, but the impact on oil and gas consumption is not significant. Therefore, it is necessary to consider other types of clean energy, such as biomass energy, solar energy and geothermal energy, to realize the linkage effect of all clean energy and promote the diversification of energy consumption structure.

\section{Acknowledgements}

The authors thank for the funding of The National Social Science Fund of China (Funding number: 14BJL045), Humanities and Social Sciences Research and Planning Fund Project of the Ministry of Education (Funding number: 18YJA810001), Shandong Academy of Social Sciences Innovation Project (Funding number: 17CCXJ07) and Qingdao Social Science Planning Project (Funding number: QDSKL1801036).

\section{References}

[1] Shandong new energy industry development plan (2018-2028), 2018, 09, 17.

[2] Zerrahn, Alexander. Wind Power and Externalities. Ecological economics, 2017, 141 (Nov): 245-260.

[3] Sorknaes P, Djorup S R, Lund H, et al. Quantifying the influence of wind power and photovoltaic on future electricity market prices. Energy Conversion and Management, 2019, 180: 312-324.

[4] Johansen Leif. A Multi-Sectoral Study of Economic Growth. Amsterdam: North-Holland, 1960.

[5] He, Y X., Liu, Y. Y. Low-carbon-oriented dynamic optimization of residential energy pricing in China. Energy, 2014, 66: 610-623.

[6] Dixon P. B., Jerie M., Rimmer M. T. (2018) Calibration and Parameter Estimation for a Melitz Sector in a CGE Model. In: Trade Theory in Computable General Equilibrium Models. Advances in Applied General Equilibrium Modeling. Springer, Singapore.

[7] Gao Y, Wang X Y, ZHANG B L, et al. Changes of Social and economic Sectors and Factors in Beijing under different water pollution purification scenarios: An analysis based on THE ES-CGE Model. Journal of Ecology, 2018, 38 (5): 1668-1678. 
[8] Hu Q. Research on the Impact of Carbon tax Policy based on CGE Model on China's Economic Structure. Jiangnan University, 2017.

[9] Zhang Y. Research on Renewable Energy Price Policy in Inner Mongolia [D]. Inner Mongolia University, 2015.

[10] Lin F. Research on optimization of New Energy Fiscal and Tax Policies in Inner Mongolia. Marketing, 2019 (51): 110+112.

[11] Wang P, Liu X Y, Hu B, et al. Economic Analysis of carbon tax Policies in three Northeast Provinces based on CGE Model. Business News, 2020.

[12] Zhang W J, Ma X L. Effect and cost of haze Reduction by Environmental Tax -- Based on dynamic Multi-region CGE Model. Journal of Beijing Institute of Technology (Social Sciences), 2020 (3).

[13] Wang Q W., Li S T. Principle, method and application of social accounting matrix. Beijing: Tsinghua university, 2008.

[14] Pauw K. Functional forms used in CGE models: Modelling production and commodity flows. 2003.
[15] He Y X, Zhang S L, Yang L Y, et al. Economic analysis of coal price-electricity price adjustment in China based on the CGE model. Energy Policy, 2010, 38 (11): 6629-6637.

[16] Wang K, Wang C, Chen J. Analysis of the economic impact of different Chinese climate policy options based on a CGE model incorporating endogenous technological change. Energy policy, 2009, 37 (8): 2930-2940

[17] Schaefer A, Jacoby H D. Technology detail in a multisector CGE model: transport under climate policy. Energy Economics, 2005, 27 (1): 1-24.

[18] Bisschop J, Meeraus A. On the development of a general algebraic modeling system in a strategic planning environment. Applications. Springer, Berlin, Heidelberg, 1982: 1-29.

[19] Bussieck M R, Meeraus A. General algebraic modeling system (GAMS). Modeling languages in mathematical optimization. Springer, Boston, MA, 2004: 137-157. 